\title{
The highly efficient gamma-neutron detector for control of fissionable radioactive materials
}

\author{
V.D.Ryzhikov*, B.V.Grinyov", G.M.Onyshchenko ${ }_{*}^{*}, *$, \\ L.A.Piven,", S.V.Naydenov ${ }^{*, * *}$, O.K.Lysetska \\ "Institute for Scintillation Materials, STC "Institute for Single Crystals", National \\ Academy of Sciences of Ukraine, 60 Lenin Ave., 61001 Kharkiv, Ukraine \\ * V.Karazin Kharkiv National University, \\ 4 Svobody Sq., 61022 Kharkiv, Ukraine \\ Institute for Single Crystals, STC "Institute for Single Crystals", National \\ Academy of Sciences of Ukraine, 60 Lenin Ave., 61001 Kharkiv, Ukraine
}

\section{Received March 13, 2014}

\begin{abstract}
Comparative measurements and analysis of detection efficiency of fast and thermal neutrons from ${ }^{239} \mathrm{Pu}$-Be source by heavy oxide scintillators $(Z \geq 50)$ confirmed high detection efficiency $(\sim 40-50 \%)$. The most probable mechanism determining the fast neutron detection efficiency is the reaction of inelastic scattering $\left(n, n^{\prime} \gamma\right)$ as the main mechanism of interaction of neutrons with nuclei of oxide scintillators. The fast neutron detection efficiency was determined by the method of internal counting of gamma-quanta emerging in the scintillator under $\left(n, n^{\prime} \gamma\right)$ reaction. It has been shown that the use of heavy oxide scintillators (which are also efficient gamma-detectors) in inspection systems can allow detection of fissionable radioactive materials.
\end{abstract}

Приводится анализ әффективности регистрации быстрых и тепловых нейтронов ${ }^{239} \mathrm{Pu}-$ Ве источника тяжелыми неорганическими оксидными сцинтилляторами $(Z \geq 50)$, подтверждена высокая әффективность детектирования 40-50\%. Показано, что наиболее вероятным механизмом, ответственным за әффективность регистрации быстрых нейтронов, является реакция неупругого рассеяния $\left(n, n^{\prime} \gamma\right)$. Показано, что использование в инспекционных системах тяжелых оксидных сцинтилляторов, которые в то же время являются әффективными гамма-детекторами, позволит обнаруживать делящиеся радиоактивные материалы.

Високоефективні гамма-нейтронні детектори для контролю радіоактивних матеріалів, що діляться. В.Д.Рижиков, Б.В.Гриньов, Г.М.Онищенко, Л.А.Пивень, С.В.Найдъонов, О.К.Лисецька.

Приводиться аналіз ефективності реєстрації швидких і теплових нейтронів ${ }^{239} \mathrm{Pu}-\mathrm{Be}$ джерела важкими неорганічними оксидними сцинтиляторами $(Z \geq 50)$, підтверджено високу ефективність детектування $\sim 40-50 \%$. Показано, що найбільш вірогідним механізмом, відповідальним за ефективність реєстрації швидких нейтронів, є реакція непружного розсіяння $\left(n, n^{\prime} \gamma\right)$. Показано, що використання в інспекційних системах важких оксидних сцинтиляторів, які в той же час є ефективними гамма-детекторами, дозволить виявляти радіоактивні матеріали, що діляться.

\section{Introduction}

Traditional inspection systems involving large-sized organic scintillators in gamma- detection blocks and ${ }^{3} \mathrm{He}$ or ${ }^{10} \mathrm{~B}$ neutron counters placed in polyethylene moderators have low reliability due to drawbacks of gas 
counters. Also, detection efficiency of fast neutrons by such counters is limited by the value of $<10 \%$ due to low moderating efficiency (the same $10 \%$ ). Such detection systems are rather expensive because of their large mass and size and practically linearly depend from window area. Thus, it is worthwhile to consider alternative methods for neutron detection.

Fissionable radioactive materials $(\mathrm{U}, \mathrm{Pu})$ are sources of both neutrons and gammarays. Therefore, to achieve high detection efficiency in inspection systems, it is most appropriate to simultaneously detect both gamma and neutron radiation [1-4]. Of special interest is the possibility of using heavy oxide scintillators to create highly sensitive gamma-neutron detectors. A sufficiently high detection efficiency of both fast neutrons and gamma-quanta by one and the same detector would significantly increase the sensitivity of inspection systems, and enable significant reduction of their size and cost [3].

In this work fast neutron detection efficiencies for heavy oxide scintillators were determined by the method of internal counting of gamma-quanta emerging in the scintillator with energies in the range of 20$1000 \mathrm{keV}$ [4-7], whereas among the most probable interactions between fast neutrons and matter is the reaction of inelastic scattering $\left(n, n^{\prime} \gamma\right)[2-8]$. This mechanism is further enhanced for heavy atomic materials and hence in oxide scintillators with heavy atomic constituents.

\section{Experimental}

Efficiency measurements for the detection of fast neutrons from a ${ }^{239} \mathrm{Pu}-\mathrm{Be}$ source by the heavy oxide scintillators $\mathrm{Gd}_{2} \mathrm{SiO}_{5}$ (GSO), $\mathrm{Bi}_{4} \mathrm{Ge}_{3} \mathrm{O}_{12}$ (BGO), $\mathrm{CdWO}_{4}$ (CWO) and $\mathrm{ZnWO}_{4}$ (ZWO), as well as the alkali halide scintillators CsI(TI), $\mathrm{ZnSe}(\mathrm{Te}, \mathrm{O}), \mathrm{Nal}(\mathrm{Tl})$ and $(\mathrm{Lil}(\mathrm{Eu}))$ [2] were made using a scintillation gamma spectrometer [3]. To obtain unambiguous correspondence between a neutron interaction event and the appearance of a counting pulse in the working window of the detection system, the spectrometric signal integration time constant was chosen to be sufficiently high $(30 \mu \mathrm{s})$ and equal for all scintillators.

Since ${ }^{239} \mathrm{Pu}-\mathrm{Be}$ neutron sources are also the source of significant gamma-ray emissions, we used a procedure allowing us to passively exclude the gamma-background by shielding the source with lead protection $[9,10]$.

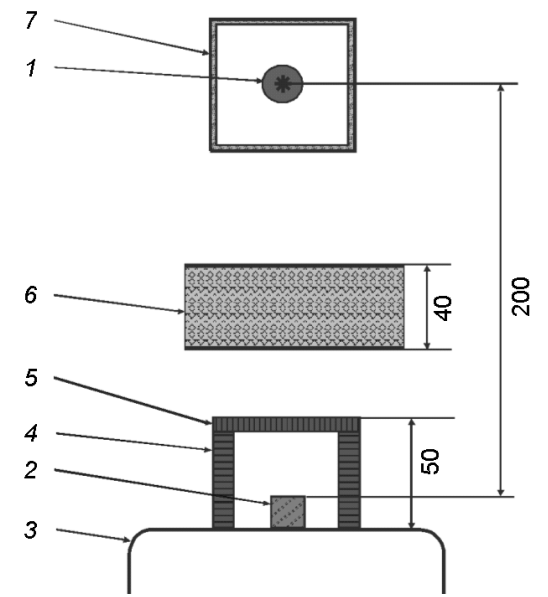

Fig. 1. Design of the experimental apparatus for recording of total (direct and scattered) fast neutron radiation. $1-{ }^{239} \mathrm{Pu}-\mathrm{Be}$ source of fast neutrons; $2-$ scintillator under study, dimensions $10 \times 10 \times 10 \mathrm{~mm}^{3} ; 3-\mathrm{PMT}$ of Hamamatsu R1306 type; 4 - cylindrical absorber of thermal neutrons made of gadolinium oxide, $\varnothing=40 \mathrm{~mm}, d=10 \mathrm{~mm} ; 5-$ lid of gadolinium oxide, $d=10 \mathrm{~mm} ; 6-$ lead shield, $h=40 \mathrm{~mm} ; 7-$ lead shield, $d=4 \mathrm{~mm}$.

Also investigated were measurements with detector design variations, including the use of an electronic detection window for gamma-quanta chosen in the energy range from 20 to $300 \mathrm{keV}$, to provide active protection. We determined that a considerable ( $\sim 10^{3}$ times) reduction in the level of registration of scattered external high-energy gamma rays can be achieved [2, 9, 10]. The neutron detection efficiencies for the tested heavy oxide scintillators were measured to be in the range of approximately $40-50 \%$ [2].

The general design of the experimental apparatus is shown in Fig. 1. For absorption of thermal neutrons, we used absorbers made of compacted gadolinium oxide of $10 \mathrm{~mm}$ thickness. The choice of gadolinium oxide over cadmium (Cd) was due to the much lower level of gamma-radiation noise in the working range of the spectrometer.

The apparatus also included electronic processing of the photomultiplier tube (PMT) output, though this is not shown in the sketch. From an amplifier-shaper output, the signals come to an analog-to-digital converter (ADC) input in the energy range of gamma-quanta recording from 20 to $1000 \mathrm{keV}$. The measured value in the experiments is the number of spectrometer pulses in the working window during the given time interval. 
Table 1. Measured efficiency (\%) of detection of fast and thermal neutrons from Pu-Be source by different scintillators in the equivalent energy range for electrons (gamma-quanta) 20$1000 \mathrm{keV}$

\begin{tabular}{|c|c|c|c|c|c|c|c|c|c||}
\hline Scintillator & ZnSe(O,Te) & Nal & 6 Lil(Eu) & Csl & GSO & ZWO & CWO & BGO & $\begin{array}{c}\text { 6Lil(Eu) from } \\
\text { reaction } \\
6 \mathrm{Li}(n, \alpha) T\end{array}$ \\
\hline$Z_{\text {eff }}$ & 33 & 51 & 52 & 54 & 59 & 61 & 66 & 75 & 52 \\
\hline $\begin{array}{c}\text { Detection efficiency } \\
\text { of fast neutrons, \% }\end{array}$ & 43 & 18 & 25 & 20 & 46 & 54 & 42 & 48 & 0.25 \\
\hline $\begin{array}{c}\text { Detection efficiency } \\
\text { of fast neutrons } \\
\text { with moderator, \% }\end{array}$ & 75 & 24 & 30 & 25 & 90 & 70 & 46 & 83 & - \\
\hline $\begin{array}{c}\text { Detection efficiency } \\
\text { of thermal neutrons, \% }\end{array}$ & - & 30 & 90 & - & 65 & 44 & 67 & 34 & 93 \\
\hline
\end{tabular}

The distance between the neutron source $\left.{ }^{239} \mathrm{Pu}-\mathrm{Be}\right)$ and the crystal under study was chosen as $200 \mathrm{~mm}$. The distance from the apparatus to the nearest room walls was about $1.5 \mathrm{~m}$. The between the neutron source and the scintillator under study, a lead shield (i.e., a $40 \mathrm{~mm}$ thick square plate of $70 \mathrm{~mm}$ side dimension) was placed for shielding of the detector and measurement equipment from the gamma radiation of the source. The source was also surrounded by thin lead shield of $4 \mathrm{~mm}$ thickness to reduce the effects of scattered ( $E=59.54 \mathrm{keV}$ from the admixture of ${ }^{241} \mathrm{Pu}$ in the source) low-energy radiation of the ${ }^{239} \mathrm{Pu}-\mathrm{Be}$ source.

Cosmic radiation background was also measured and accounted for in processing of the obtained data. The statistical error in the experiment did not exceed $1 \%$.

The measurements of fast neutron detection efficiency for the various scintillators tested were carried out in the following way. We assumed that the following categories of radiation reach the detector from the fast neutron source: fast neutrons (FN) directly from the source reactions, scattered fast neutrons (SFN) from the walls, thermal neutrons (TN) from the moderator (in the case where a moderator is inserted around the scintillator) and the source, and scattered thermal neutrons (STN). Additional details of our experiment were described previously in $[2,9-11]$.

\section{Results and discussion}

In a previous study, we have considered mechanisms of the reaction $\left(n, n^{\prime} \gamma\right)$ that can substantially increase the fast neutron detection efficiency by scintillators in the energy range from 20 to $300 \mathrm{keV}$ [2, 3, 9, 10].

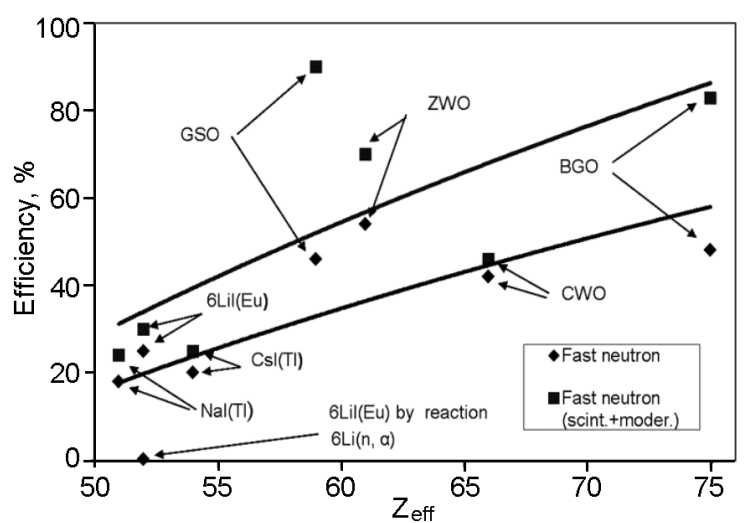

Fig. 2. Detection efficiency (\%) of fast neutrons from ${ }^{239} \mathrm{Pu}-\mathrm{Be}$ source by oxide and alkali-halide scintillators based on the reaction $\left(n, n^{\prime} \gamma\right)$ in equivalent gamma-quanta energy range $20-1000 \mathrm{keV}$.

The thermal neutron (TN) flux density was evaluated as the difference between the total neutron flux and the fast neutron flux: $\quad \mathrm{TN}=[\mathrm{FN}+\mathrm{SFN}+\mathrm{TN}]-[\mathrm{FN}+\mathrm{SFN}]$. Thus, it is not necessary to individually determine FN and SFN, since they are automatically accounted for in this TN calculation.

Table 1 and Fig. 2 show the experimental data obtained for $\mathrm{FN}$ detection efficiency from ${ }^{239} \mathrm{Pu}-\mathrm{Be}$ source by the oxide and alkali-halide scintillators based on the reaction $\left(n, n^{\prime} \gamma\right)$ in equivalent gamma-quanta energy range 20-1000 keV.

Also included in both the Table and the Figure are the results for the case when the detector was surrounded by a thin layer of moderator (diameter $d \sim 1 \mathrm{~cm}$ ).

Thus, the obtained results demonstrate the correlation between detection efficiency and the effective atomic number $Z_{\text {eff }}$ of the crystalline scintillation material. 


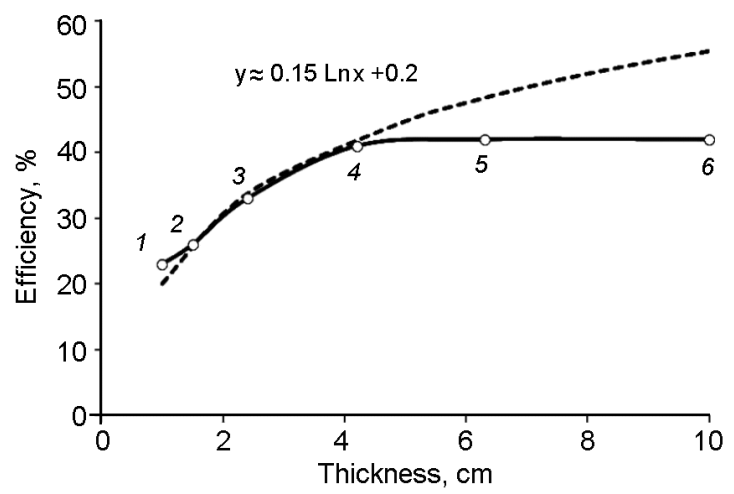

Fig. 3. Fast neutron detection efficiency as function of CWO scintillator thickness. Dashed line represents a projected logarithmic dependence (in absolute units) corresponding to the first 4 thickness values.

The results are in agreement with the data presented in $[12,13]$ and are also consistent with the known dependence of fast neutron scattering cross-section on atomic mass [14]. In the gamma-radiation energy range $E_{\gamma}$ from 20 to $1000 \mathrm{keV}$ the neutron detection efficiency by heavy oxide scintillators reaches $54 \%$ for $\mathrm{ZWO}(\mathrm{FN})$ and $67 \%$ for CWO (TN). With a moderator of small thickness $(d \sim 1 \mathrm{~cm}), \mathrm{FN}$ detection efficiency can be as high as $\sim 90 \%$ for GSO. It should also be noted that the neutron detection efficiency of Lil(Eu) [2] scintillators measured by our method gives results that are higher by more than an order of magnitude than that measured by standard methods. The neutron registration efficiencies for standard (traditional) approaches were measured and it was not greater than $0.25 \%$ [11].

It is well known that the scattering processes experienced by FN lead to a transformation of their energy spectra in reaction ( $\left.n, n^{\prime} \gamma\right)$ towards lower energies [2, 12]. This

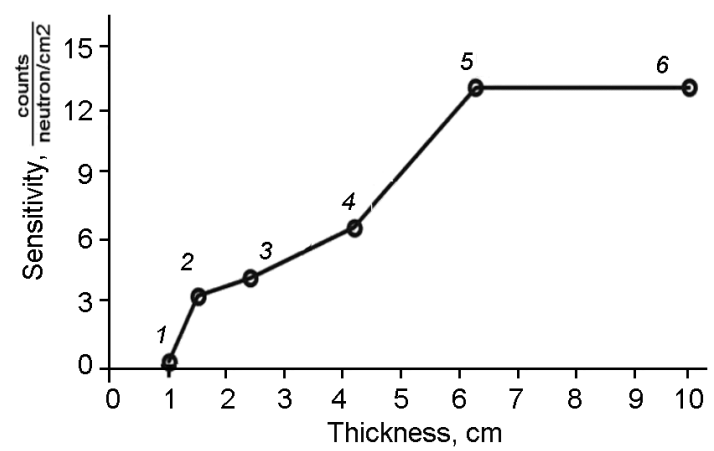

Fig. 4. Sensitivity of CWO scintillator as function of thickness in detection of fast neutrons.

results in progressively higher intensity of SFN with much lower (by orders of magnitude) energy, until the neutrons reach low energies where the capture cross-sections $\sigma(n, \gamma)$ become more important. This, in turn, enables increases in the detection efficiency of FN using the method of detection described in this paper [4-10].

The dependence of neutron detection efficiency (relation of number of registered neutrons per second to number of incident neutrons) and detector sensitivity (relation of number of registered neutrons to density flux of incident neutrons) on the detector dimension for scintillators of different volumes (thickness and cross sectional area) was investigated (see Table 2 and Fig. 3, 4). Fig. 3 demonstrates the impact of thickness on detector efficiency with measurements with six thicknesses of CWO scintillator crystal. Initially the detector efficiency increases by a slow logarithmic dependence (see No.1-4 in the Table 2). It was demonstrated that this increase in efficiency can be observed for the heavy oxide scintillator (CWO) only up to a thickness of $4-5 \mathrm{~cm}$ and

Table 2. Efficiency and sensitivity of fast neutron detection as function of input window area and thickness for scintillator CWO

\begin{tabular}{|c|c|c|c|c|}
\hline Crystal, No. & Thickness, cm & Efficiency, \% & Window area, $\mathrm{cm}^{2}$ & $\begin{array}{c}\text { Sensitivity, } \\
\text { counts } / \text { neutron }^{-\mathrm{cm}^{2}}\end{array}$ \\
\hline 1 & 1.0 & 23 & 1.0 & 0.2 \\
2 & 1.5 & 26 & 12.7 & 3.3 \\
3 & 2.4 & 33 & 12.6 & 4.1 \\
4 & 4.2 & 41 & 15.9 & 6.5 \\
5 & 6.3 & 42 & 31.2 & 13.1 \\
6 & 10.0 & 42 & 31.2 & 13.1 \\
\hline
\end{tabular}




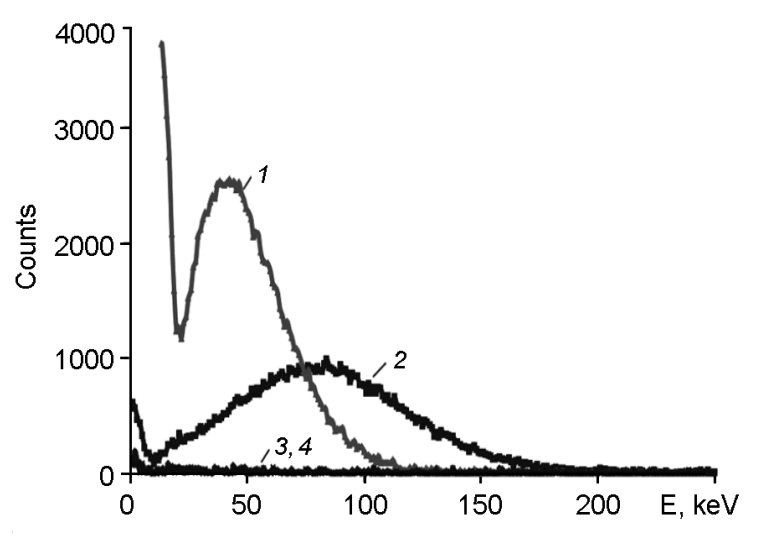

Fig. 5. Attenuation by passive protection (BGO) of gamma-radiation from sources Am241 and Co-57: 1 - gamma-spectrum from Am-241 in irradiation of detector (CWO) without protection, 2 - gamma-spectrum from Co-57 in irradiation of detector (CWO) without protection, $3-$ gamma-spectrum from Am-241 in irradiation of detector (CWO) with protection, 4 - gamma-spectrum from Co-57 in irradiation of detector (CWO) with protection.

becomes constant thereafter. This result is unexpected and will require additional investigation to develop a more complete understanding. In contrast to this finding, as shown in Fig. 4, detector sensitivity is found to increase practically linearly up to a thickness of about $6 \mathrm{~cm}$; further, the data in the Table 2 indicate that sensitivity increases linearly with increasing cross sectional area of the scintillator. It can also be noted that sensitivity of the CWO scintillator is practically a linear function of the input window area (see Table 2).

An additional advantage of using inorganic scintillators for nuclear source detection is the coincident high sensitivity at low energy threshold levels; for example, $204 \mathrm{keV}$ and $243 \mathrm{keV}$ for ${ }^{238} \mathrm{U}$, and $129 \mathrm{keV}$ and $424 \mathrm{keV}$ for ${ }^{239} \mathrm{Pu}$.

So, to achieve the highest sensitivity levels, it is useful to apply simultaneously the detection of gamma and neutron fluxes. In future work, we will attempt to distinguish between these two types of simultaneous detections.

To produce a pure fast neutron detector, without interference from gamma-radiation from the environment or from a combined neutron-gamma source, it is necessary to create a special detector design by appropriately shielding the detector from the additional external gamma radiation, implementing electronic discrimination within the detector system itself, or through a combination of these approaches.

Our studies have shown that lead shielding of a $40 \mathrm{~mm}$ thickness is quite sufficient to protect from external gamma-radiation of energies up to $300 \mathrm{keV}$. However, it was also shown that high-energy external gamma-radiation, e.g., $E=661 \mathrm{keV}$ from ${ }^{137} \mathrm{Cs}$, in particular, when small-sized scintillators are used, could result in a noticeable Compton component in the scintillator, which, in the working range of $20-300 \mathrm{keV}$, could provide an additional source of measurement errors.

Therefore, we have developed and tested the design of a composite detector using the active shielding method, which allows a substantial decrease (by $\sim 10^{3}$ times) of the noise detection level in the working range caused by Compton scattering of high-energy external sources of gamma-radiation. This substantially improves the detector selectivity for neutrons in mixed gamma-neutron fields.

The active shielding method is based on the elimination of the pulses emerging simultaneously in the main and protecting scintillator as a result of Compton scattering of high-energy gamma-quanta. To achieve this, the neutron detector was made as a composite structure (of a special "phoswich" detector type [15]) on the basis of two inorganic scintillators: an external one in the shape of a ring cylinder of outer diameter $54 \mathrm{~mm}$ and inner diameter $46 \mathrm{~mm}$, a wall thickness of $8 \mathrm{~mm}$, a height of $50 \mathrm{~mm}$, with fast decay (BGO); and an internal one - the main scintillator shaped as a cylinder of diameter $45 \mathrm{~mm}$ and height $50 \mathrm{~mm}$, with long decay time (CWO). The CWO scintillator is placed inside the BGO scintillator; they have no optical connection, but are contacted with the same PMT. The preliminary signal processing block includes signal amplification shapers, an anticoincidence circuit and a microprocessor with a built-in analog-to-digital converter.

In this proposed design, two main processes can occur in the internal scintillator: inelastic scattering of fast neutrons on scintillator nuclei with direct recording of the nuclear reaction products, and radiation capture of neutrons (both fast and slow) by cadmium nuclei contained in this scintillator and possessing a large effective capture cross-section for thermal neutrons.

This allows realization of fast and thermal neutron detection by one and the same detector, which does not require the use of 


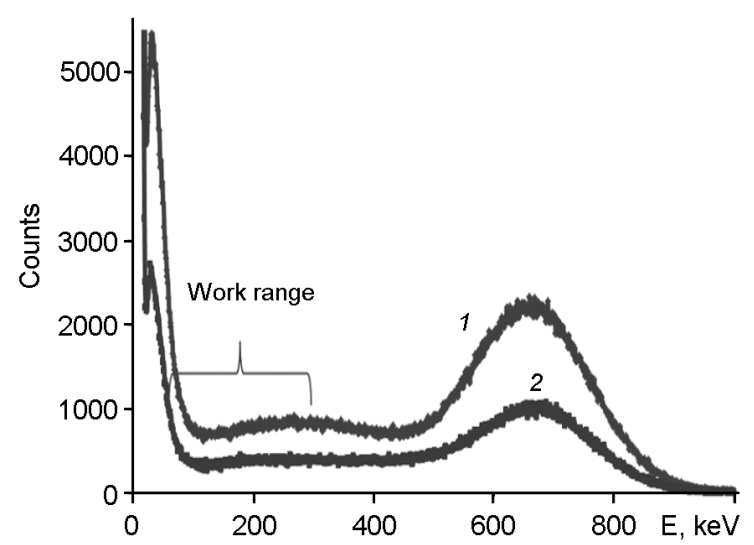

Fig. 6. Attenuation by passive protection (BGO) of gamma-radiation from ${ }^{137} \mathrm{Cs}$ source: 1 - gamma-spectrum in irradiation of detector (CWO) without protection, 2 - gammaspectrum in irradiation of detector (CWO) with attenuation by protection.

moderators (as distinct from current detection systems). This, in turn, allows substantial reduction of the detector size.

The external detector, in addition to its role as anti-coincidence detector for Compton quanta, acts also as passive protection from external gamma-quanta. Fig. 5 shows the spectra of external gamma-sources (Am241 and Co-57) obtained in irradiation of CWO without protection (that is, direct exposure onto the end face of the composite scintillator) and with protection - in irradiation from the side, i.e., with attenuation in the external protection detector BGO of $8 \mathrm{~mm}$ thickness.

It can be seen that passive BGO-protection of $8 \mathrm{~mm}$ thickness attenuates the external flux of gamma-quanta with sufficient efficiency in the working energy range 20$300 \mathrm{keV}$. When the additional active shielding is activated, the number of noise pulses in the energy range $20-300 \mathrm{keV}$ is reduced by $10^{3}$ times.

Fig. 6 shows the spectrum of an external ${ }^{137} \mathrm{Cs}$ source obtained in irradiation of a CWO-detector without protection, i.e., under irradiation without attenuation in the external detector BGO, and with protection, i.e., with attenuation.

One can see that in the working energy range there is substantial noise due to Compton scattering of Cs-137 gamma-radiation. When the active protection is activated, the number of noise pulses in the energy range $20-300 \mathrm{keV}$ is again reduced by about $10^{3}$ times.

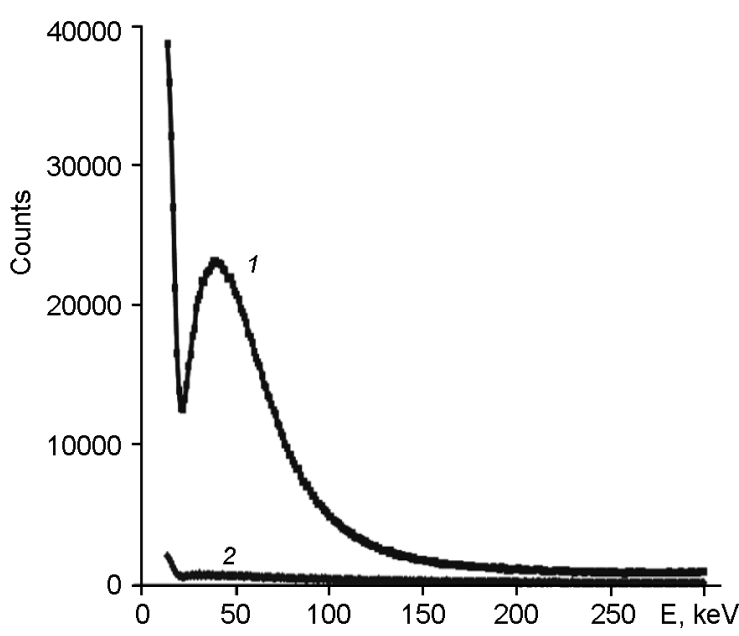

Fig. 7. Attenuation by passive protection (BGO) of mixed $n-\gamma$ radiation from ${ }^{239} \mathrm{Pu}-\mathrm{Be}$ in neutron detector (CWO) of "phoswich" design: 1 - gamma-spectrum in irradiation of detector without protection, 2 - gamma-spectrum in irradiation of detector with protection.

Fig. 7 illustrates the degree of attenuation by the passive protection (BGO crystal) of mixed $n-\gamma$-radiation from a ${ }^{239} \mathrm{Pu}-\mathrm{Be}$ source in the composite neutron detector. The upper spectrum was obtained in irradiation of the detector without protection, and that below - in irradiation from the side, i.e., using passive protection.

\section{Conclusions}

The phenomenon of neutron inelastic scattering $\left(n, n^{\prime} \gamma\right)$ on nuclei of heavy oxide scintillators allows the creation of high efficiency neutron detectors. In these detectors, the energy of fast neutrons is directly converted to the energy of gamma-quanta, which allows substantial (by 10 times) increase in detection efficiency and sensitivity (with corresponding reduction in costs) of systems for detection of fissionable radioactive substances as compared with traditional systems. In some cases, e.g., for $\mathrm{Nal}(\mathrm{TI})$, an additional mechanism that can be used to increase fast neutron detection efficiency is estimation of instantaneous gamma-quanta from $\mathrm{FN}$ radiation capture reactions.

Suppression of external gamma-radiation is possible using an active shielding method, which increases the detection selectivity of fast neutrons on the background of external gamma-radiation. This broadens the application range of fast neutron detectors using the neutron inelastic scattering reaction $\left(n, n^{\prime} \gamma\right)$ on scintillator nuclei. 
In a compound detector assembly, an external heavy scintillator also provides passive attenuation of the external gamma-radiation in the working energy range $20-300 \mathrm{keV}$.

It should also be noted that limiting the working range to energies up to $300 \mathrm{keV}$ excludes detection of photo-peaks from external gamma-quanta above $300 \mathrm{keV}$ and also weakens the influence of external gamma-radiation on the detector.

The design of the neutron counter as a "phoswich" detector composed of fast and slow oxide scintillators in combination with optimum filtration simultaneously in both scintillators as a result of Compton scattering of external high energy gamma-quanta.

Application of all these factors allows a decrease in the pulse counting due to external gamma-quanta of signals of different duration coming from different scintillators enable us to avoid recording of pulses emerging by about one thousand times (depending on the experimental conditions). The neutron detection efficiency is only slightly lowered. As a result, this allows the creation of FN detectors capable of functioning in mixed gamma-neutron fields. The results obtained can be useful for development of new types of devices and instruments for detection of neutrons and definition of fissionable materials in nuclear security systems.

High efficiency of FN detection was also demonstrated with the alkali halide scintillators $\mathrm{Nal}(\mathrm{Tl}), \mathrm{Csl}(\mathrm{TI})$ and $\mathrm{Lil}(\mathrm{Eu})$. This opens possibilities of substantial improvement of standard monitoring portals with spectrometric blocks on the basis of $\mathrm{Nal}(\mathrm{TI})$ or CsI(TI) for detection of FN fluxes accompanied with gamma radiation [16]. The presented experimental results show that the FN detection efficiencies of different crystals are proportional to the thickness of the crystal in the range of $10-40 \mathrm{~mm}$ and do not depend on the thickness of the crystal in the range of $40-100 \mathrm{~mm}$.

Acknowledgements. This work was supported in part by NATO project SfP984605 .

\section{References}

1. Ukraine Patent No.80455 (2007).

2. V.D.Ryzhikov, B.V.Grynyov, G.M.Onyshenko et al., in: Tendentsiya Razvitiya Scintillatsionnoy Tehniki, ISMA, Kharkov (2013), p.171 [in Russian].

3. V.D.Ryzhikov, B.V.Grinyov, G.M.Onyshchenko et al., IEEE Trans.Nucl.Sci., 57, 2747 (2010).

4. M.Anelli, G.Battistoni, S.Bertolucci et al., Nucl.Instr. Meth. Phys. Res. A, 580, 368 (2007).

5. V.D.Ryzhikov, B.V.Grinyov, G.M.Onishchenko et al., in: Proc. First Intern. Conf. on Advanc. in Nucl. Instrum., Measur. Meth. and their Appl. (ANIMMA 2009), Marseile, France (2009), p.188.

6. U.S. Patent 8,058,624 (2011).

7. Ukraine Patent No.96428. (2010).

8. Ukraine Patent No.92193. (2010).

9. V.Ryzhikov, B.Grynyov, G.Onishcenko et al., Telecommun. and Radio Engin., 71, 1665 (2012).

10. V.Ryzhikov, B.Grynyov, G.Onishcenko et al., Zbirnyk Naukovyh Prats' SNUYAEtaP, 44, 170 (2012).

11. N.Avaev, G.A.Vasilyev, A.P.Veselkin et al., Experimental Studies of Gamma-radiation and Neutron Fields, Atomizdat, Moscow (1974) [in Russian].

12. N.A.Vlasov, Neutrons, Nauka, Moscow (1971) [in Russian].

13. J.M.Blatt, V.F.Weusskopf, Theoretical Nuclear Physics, Inostr. Literatura, Moscow (1954) [in Russian].

14. A.Akhiezer, I.Pomeranchuk, Nekotorye Voprosy Teorii Yadra, Techn. Literatura, Moscow (1950) [in Russian].

15. Yu.K.Akimov, Stsintillyatsionnye Metody Registratsii Chastic Bolshikh Energiy, MGU, Moscow (1963) [in Russian].

16. V.Rudnichenko, S.Zvezhynsky. Sovremennye Technologii Bezopasnosty, 3, 200 (2007). 